\title{
@enomic and molecular characterization of pituitary adenoma pathogenesis: review and translational opportunities
}

\author{
Mazin Elsarrag, MS, Parantap D. Patel, BS, Ajay Chatrath, MS, Davis Taylor, MD, and \\ John A. Jane Jr., MD \\ Department of Neurological Surgery, University of Virginia Health System, Charlottesville, Virginia
}

\begin{abstract}
OBJECTIVE Innovations in genomics, epigenomics, and transcriptomics now lay the groundwork for therapeutic interventions against neoplastic disease. In the past 30 years, the molecular pathogenesis of pituitary adenomas has been characterized. This enhanced understanding of the biology of pituitary tumors has potential to impact current treatment paradigms, and there exists significant translational potential for these results. In this review the authors summarize the results of genomics and molecular biology investigations into pituitary adenoma pathogenesis and behavior and discuss opportunities to translate basic science findings into clinical benefit.
\end{abstract}

METHODS The authors searched the PubMed and MEDLINE databases by using combinations of the keywords "pituitary adenoma," "genomics," "pathogenesis," and "epigenomics." From the initial search, additional articles were individually evaluated and selected.

RESULTS Pituitary adenoma growth is primarily driven by unrestrained cell cycle progression, deregulation of growth and proliferation pathways, and abnormal epigenetic regulation of gene expression. These pathways may be amenable to therapeutic intervention. A significant number of studies have attempted to establish links between gene mutations and tumor progression, but a thorough mechanistic understanding remains elusive.

CONCLUSIONS Although not currently a prominent aspect in the clinical management of pituitary adenomas, genomics and epigenomic studies may become essential in refining patient care and developing novel pharmacological agents. Future basic science investigations should aim at elucidating mechanistic understandings unique to each pituitary adenoma subtype, which will facilitate rational drug design.

https://thejns.org/doi/abs/10.3171/2020.3.FOCUS20104

KEYWORDS pituitary tumor genomics; translational research; pituitary adenoma pathogenesis

$\mathrm{A}$ DVANCES in genomics and molecular biology have revolutionized the practice of oncology in a relatively short amount of time. The diagnosis, classification, management, and prognostication of most tumor types are now directly guided by tumor genomics. Innovations in genomics and molecular biology have helped us work toward a more detailed understanding of the sequence and cellular events of tumorigenesis, which in turn provides a basis for refined clinical management and rational targets for therapeutic interventions. However, changes to clinical practice do not always immediately follow advances in basic science knowledge. This is particularly true when one considers the diagnosis, management, and prognostication of pituitary tumors, which have not seen many major innovations in recent years, in spite of an increasingly detailed understanding of the genomic landscape and molecular processes contributing to tumor pathogenesis and clinical behavior. In this review, we present a summary of the molecular pathology and genomic landscape of spontaneous benign pituitary adenomas, their effect on clinical behavior of the tumors, and translational opportunities and future directions in the management of these tumors.

\section{Molecular and Cellular Pathogenesis of Pituitary Adenoma \\ Overview}

The term "pituitary adenoma" encompasses a tremendous variety of tumors arising from the anterior pituitary

ABBREVIATIONS ACTH = adrenocorticotropic hormone; $\mathrm{GH}=$ growth hormone; $\mathrm{PRL}=$ prolactin; $\mathrm{TSH}=$ thyroid-stimulating hormone.

SUBMITTED February 1, 2020. ACCEPTED March 9, 2020.

INCLUDE WHEN CITING DOI: 10.3171/2020.3.FOCUS20104. 
gland. Whereas most are slow growing and benign, a significant percentage of tumors demonstrate invasive behavior or have high recurrence rates, making them challenging to treat. ${ }^{1}$ Pituitary adenomas are associated with significant patient morbidity and healthcare costs, and may lead to hormone over- or undersecretion, visual defects, and other disabilities.22,32 Most evidence suggests that these tumors are monoclonal, indicating they are the result of uncontrolled expansion of a single, somatically

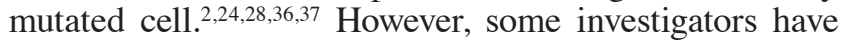
provided evidence for multiclonality in some pituitary adenomas. ${ }^{12-14}$ The exact cell of origin is unknown and may in fact differ among tumors, but tumors are typically well differentiated on histology ${ }^{45,46}$ Candidates for the cell of origin include a differentiated or progenitor anterior pituitary cell ${ }^{39}$ or pituitary stem cells., ${ }^{923}$ Pituitary adenomas have traditionally been grouped based on the cell of origin (thyrotroph, gonadotroph, somatotroph, etc.), which can be determined by histological stains. However, the pathogenesis of these tumors varies both between and among subtypes, and a single unifying explanation for how and why pituitary adenomas arise has not yet been elucidated. A summary of this section can be found in Table 1 and Fig. 1, which list and briefly describe the involved cellular processes.

\section{Unrestrained Cell Cycle Progression}

Uncontrolled progression through the cell cycle is a primary driver of pituitary adenoma growth. ${ }^{44,53,64} \mathrm{pl6/}$ CDKN2A, an important tumor suppressor that halts progression through the G1/S checkpoint, is downregulated in 56\% of pituitary adenomas. ${ }^{64}$ The loss of p16 is hypothesized to be an early event. ${ }^{18}$ Interestingly, p16 is rarely mutated and is almost always inactivated by epigenetic silencing (via methylation). ${ }^{18,64}$ Other components of the retinoblastoma $(\mathrm{Rb})$ pathway, which regulates progression through the G1/S checkpoint, are frequently deregulated in pituitary adenomas. ${ }^{44}$ Cyclin D1, which activates CDK4/6 and permits progression through the G1/S checkpoint, has also been shown to be upregulated in pituitary adenomas. Cyclin D1 overexpression may represent another insult to the integrity of the cell cycle, and may function synergistically with other mutations in cell cycle proteins. Studies have shown that as many as $50 \%$ of pituitary tumors demonstrated cyclin D1 overexpression. ${ }^{25}$

Overall, deregulation in the Rb/p16/cyclin D1/CDK4 pathway is present in up to $80 \%$ of pituitary adenomas. ${ }^{42}$ Because the primary function of the G1/S checkpoint is to permit the cell to repair DNA damage before DNA replication, it is possible that deregulation of this checkpoint allows the cell to accumulate additional mutations, which drive uncontrolled proliferation. The mechanism of this deregulation is generally epigenetic silencing (in the case of tumor suppressors), identifying aberrant epigenetic regulation as one of the master switches orchestrating pituitary tumor genesis and growth. ${ }^{64}$

\section{Deregulation of Growth and Proliferation Pathways}

One of the hallmarks of tumorigenesis is an imbalance in pro- versus antiproliferative cellular signaling. This ab-
TABLE 1. Primary affected pathways in pituitary adenoma and role in tumorigenesis

\begin{tabular}{|c|c|}
\hline Cellular Process & Role in Tumorigenesis \\
\hline $\begin{array}{l}\text { Aberrant epigenetic } \\
\text { gene control }\end{array}$ & $\begin{array}{l}\text { A significant number of tumor suppressors in } \\
\text { pituitary adenomas are downregulated via } \\
\text { epigenetic mechanisms (e.g., methylation), } \\
\text { often without somatic mutations. }\end{array}$ \\
\hline $\begin{array}{l}\text { Cell cycle deregula- } \\
\text { tion }\end{array}$ & $\begin{array}{l}\text { Tumor suppressors involved in cell cycle check- } \\
\text { points are typically downregulated (e.g., p16, } \\
R b) \text {, along with upregulation of proteins that } \\
\text { promote cell cycle progression (e.g., cyclin D). } \\
\text { A mutation in at least } 1 \text { cell cycle regulator is } \\
\text { found in the majority of adenomas. }{ }^{19}\end{array}$ \\
\hline $\begin{array}{l}\text { Growth signaling } \\
\text { imbalance }\end{array}$ & $\begin{array}{l}\text { Evasion of growth suppressors (e.g., GADD45y, } \\
\text { MEG3) along with upregulation of pro-prolifer- } \\
\text { ative proteins (e.g., PTTG) and excess of tro- } \\
\text { phic factors leads to excessive proliferation. }\end{array}$ \\
\hline Other & $\begin{array}{l}\text { Other factors that may contribute to pituitary } \\
\text { adenoma oncogenesis include cancer stem } \\
\text { cells, hypothalamic hyperstimulation, and } \\
\text { atypical microRNA expression profiles. }\end{array}$ \\
\hline
\end{tabular}

erration can be seen in pituitary adenoma cell signaling, which reveals both a decrease in growth suppression signals and an excess of progrowth signaling. For instance, downregulation of GADD45 $\gamma$, a protein involved in the cellular response to DNA damage and a negative regulator of cell growth, has been observed in the majority of human pituitary adenomas. ${ }^{7,41}$ Another tumor suppressor that is frequently downregulated in pituitary adenomas is $M E G 3$, a gene that encodes for a long noncoding RNA (lncRNA). ${ }^{7,4}$ Normally, MEG3 suppresses tumor cell growth, in part by its upregulation of p53 and p53-dependent processes. ${ }^{65} \mathrm{p} 53$, an instrumental tumor suppressor, is rarely mutated in pituitary adenoma, ${ }^{14}$ although the p53 pathway when examined as a whole is frequently dysregulated. ${ }^{64}$ The genes encoding GADD45 $\gamma$ and MEG3 are typically not mutated, but rather their expression levels are decreased ${ }^{7,41}$ further underscoring the importance of epigenetic dysregulation in pituitary oncogenesis.

Pituitary tumor-transforming gene $(P T T G)$ has been identified as a proto-oncogene with a major role in pituitary adenoma tumorigenesis. Originally isolated from rat pituitary tumor cells, ${ }^{63}$ PTTG has since been found to be overexpressed in $90 \%$ of pituitary adenomas. ${ }^{56}$ PTTG is a human securin protein, functioning to halt the onset of anaphase and prevent separation of sister chromatids until all chromosomes are properly assembled at the metaphase plate. Given its direct role in mitosis, aneuploidy and chromosomal instability are consequences of abnormal PTTG expression. ${ }^{31}$ It is hypothesized that PTTG contributes to tumor growth through SH3-mediated signal transduction pathways and activation of growth factors. ${ }^{56}$ Although the exact mechanism of action of PTTG is not fully known, further elucidation of the PTTG pathway may reveal opportunities for targeted therapy.

Several investigators have suggested a role for hypothalamic hyperstimulation as a causative process in the 


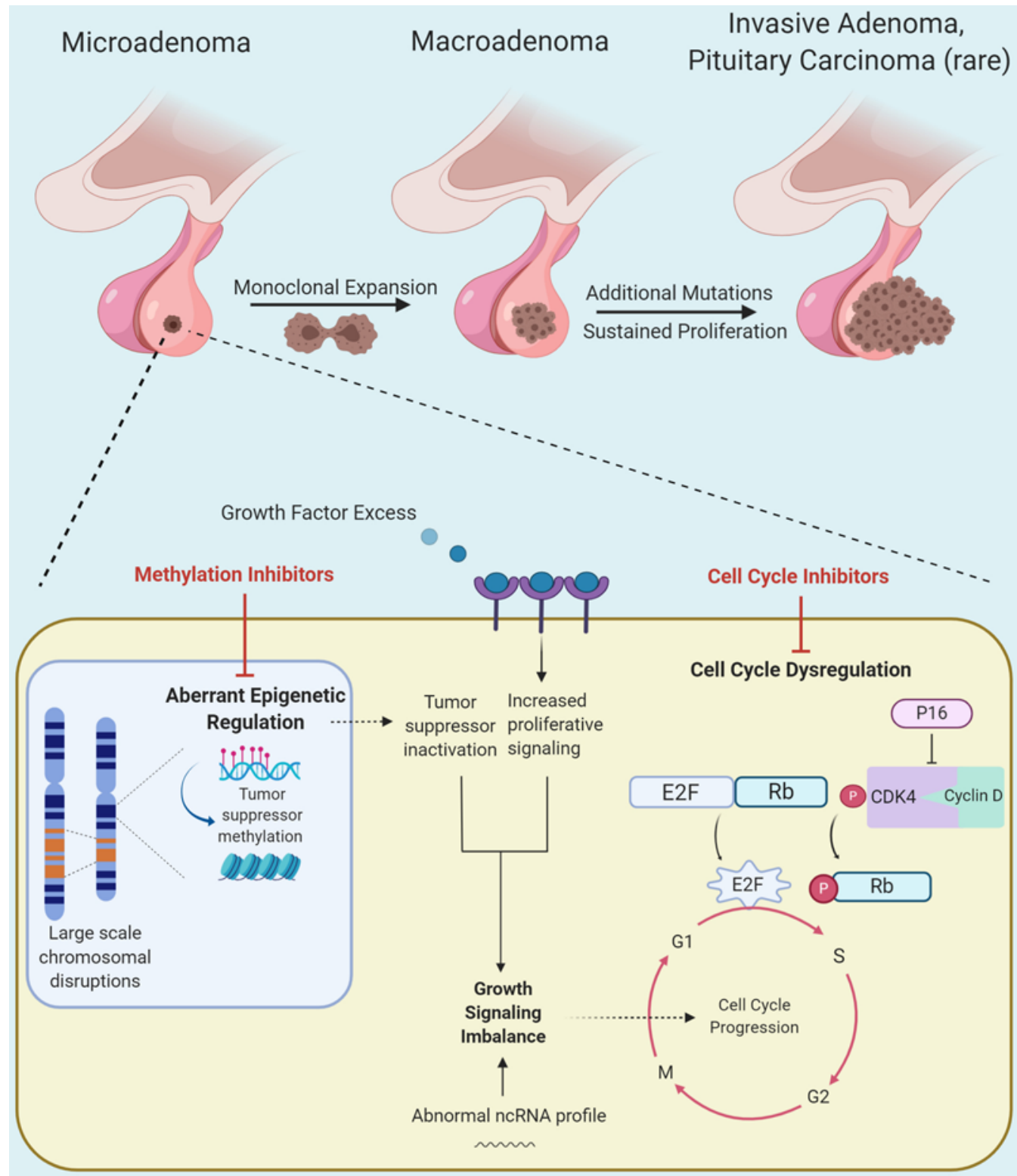

FIG. 1. Pathogenesis of pituitary adenomas. The fundamental cellular processes underlying pituitary adenoma pathogenesis are aberrant epigenetic regulation, cell cycle dysregulation, and growth signaling imbalance. Growth factor excess may be the result of local growth factors secreted by the tumor microenvironment or from hypothalamic hyperstimulation. Opportunities for clinical intervention (methylation inhibitors, cell cycle inhibitors) are shown in red. ncRNA = noncoding RNA. This figure was created using BioRender.

development of pituitary adenomas. It has been described that hypothalamic overstimulation of the pituitary gland can lead to hyperplasia and tumors, ${ }^{52}$ but the relevance of this phenomenon has been challenged..$^{12}$ Other sources of imbalance in growth signaling may be an overabundance of trophic and neurotrophic factors. ${ }^{54}$ For instance, fibroblast growth factors, which control differentiation, migration, and angiogenesis, are frequently overexpressed in pituitary adenomas. Additionally, fibroblast growth factor receptors are also upregulated in a number of pituitary adenomas when compared to healthy gland. With the advances in development of small-molecule inhibitors, these pathways may constitute viable therapeutic targets for novel treatment of pituitary adenomas.

\section{Genetic and Epigenetic Landscape of Pituitary Adenomas}

Whole-exome sequencing of matched tumor and normal samples of 42 pituitary macroadenomas found that approximately one-third of samples had chromosomal arm-level copy-number alterations. Despite a large number of tumors having chromosomal arm-level alterations, few exhibited smaller genomic events at the level of individual gene perturbations, which is unusual in comparison to other tumor types. Of the pituitary adenomas having 
large-scale genomic disruptions, $75 \%$ were functional or atypical null cell adenomas, whereas $87 \%$ of the tumors without these large-scale disruptions were nonfunctional. This finding was validated in an independent cohort of 87 pituitary adenomas. Although copy-number aberrations are commonly seen in pituitary adenomas, no recurrent mutations in any single cancer driver gene were identified. Overall, the study suggested that whether or not a pituitary adenoma is functional seems to be driven by perturbation from large-scale genomic disruptions as opposed to recurrent mutations in a single gene. With that said, the study was only sufficiently powered to test for recurrent mutations across the entire set of pituitary adenomas, suggesting that recurrent mutations in specific pituitary adenoma subtypes may exist. ${ }^{6}$

Other studies that were focused on specific pituitary adenomas have identified genomic aberrations that may drive individual subtypes. For example, previous studies have characterized recurrent somatic mutations in the deubiquitinase gene USP8 in Cushing disease, G-proteincoupled receptor GPR101 in young-onset acromegaly, and GNAS mutations in growth hormone $[\mathrm{GH}]-$ secreting pituitary adenomas. ${ }^{49,50,57}$ Sequencing of 12 prolactinomas corroborated the study of mixed pituitary adenomas; the genomes of the prolactinomas were primarily perturbed by large-scale copy-number aberrations. The authors did not identify recurrent somatic mutations in any classic driver gene in this cohort of patients. ${ }^{16}$

A study of 48 pituitary adenomas of 3 different subtypes (GH-secreting, adrenocorticotropic hormone [ACTH]secreting, and endocrine-inactive subtypes) found that somatic copy-number alterations were abundant in all 3 groups and did not identify any recurrent somatic mutations in driver genes. The authors also examined genomewide DNA methylation patterns and found that the DNA methylation patterns were unique to each tumor subtype. ${ }^{51}$ Although our focus in this review was on sporadic benign pituitary adenomas, it should be noted that the pathogenesis of inherited versus sporadic tumors is quite different. The MEN-1 tumor suppressor gene, which leads to pituitary tumors on the background of multiple endocrine neoplasia, is rarely mutated in sporadic pituitary adenomas and is therefore unlikely to play a major role in the development of this disease. ${ }^{4,19,48} A I P$, a gene that is responsible for isolated familial pituitary adenoma when mutated, is also rarely mutated in sporadic pituitary adenomas. ${ }^{29}$ Overall, the genomic studies of pituitary adenomas suggest that pituitary adenomas are primarily driven by somatic copy-number aberrations. Although it is possible that some somatic mutations may recur in individual pituitary adenoma subtypes, no recurrent somatic mutations have been identified for pituitary adenomas as a whole.

\section{Tumor Genetics and Clinical Behavior}

Despite recent advances in genomics and renewed interest in clinically applicable genomic tools for the management of malignancies, there exists a profound lack of routine genomic analyses in the management of pituitary adenomas. Below we discuss notable studies published since the release of the 2017 WHO guidelines, specifically the section titled "Classification of Tumors of the Pituitary
Gland," 35 with novel and potentially clinically valuable applications in the management of pituitary adenomas.

\section{Diagnosis and Classification}

Modern clinical practice relies on serum-based hormone assays and immunohistochemical staining of pituitary tissue, in conjunction with clinical presentation, to diagnose pituitary adenoma subtypes. ${ }^{40}$ The recent introduction of the 2017 WHO guidelines (section titled "Classification of Tumors of the Pituitary Gland") has placed emphasis on molecular genetic markers for classification purposes..$^{35}$ Per these guidelines, the concept of a "hormone-producing adenoma" is to be replaced by an adenohypophyseal cell lineage designation, determined by hormone content, histological features, and immunohistochemical features..$^{40,43}$ Particular attention is given to the assessment of transcription factors controlling tumor differentiation into defined cell lineages. These factors include the following: Pit-1 (giving rise to $\mathrm{GH}$, prolactin [PRL], and thyroid-stimulating hormone [TSH]-expressing cells); T-pit (giving rise to ACTH-expressing cells); SF-1 (giving rise to gonadotrophexpressing cells); GATA2 (expressed by gonadotroph and thyrotroph-expressing cells); and ER $\alpha$ (expressed by PRL and gonadotroph-expressing cells). Consequently, all pituitary adenomas can now be divided into 1 of 6 general categories: somatotroph, lactotroph, thyrotroph, corticotroph, gonadotroph, and plurihormonal..$^{38}$ The new system also names certain subtypes as high risk due to clinically aggressive behavior, such as the newly named plurihormonal Pit-1-positive adenoma, Crooke's cell adenoma, silent corticotroph adenoma, lactotroph adenoma in males, and sparsely granulated somatotroph adenoma. ${ }^{40}$

Limited literature has examined the clinical implications of pituitary adenoma reclassification per the 2017 WHO guidelines. Of particular research interest are previously classified "non-functioning adenomas" (lesions that do not actively secrete hormone products) and null cell adenomas (a subtype of nonfunctioning adenomas that display hormone immunonegativity). ${ }^{35}$ Notably, Almeida et al. have investigated the implications of this new classification scheme and have found that null cell adenomas (based on the new definition) are more invasive at the time of presentation and have a more aggressive clinical course, suggesting that the new classification criteria may help inform clinical decision-making. ${ }^{3}$ Transcription factor staining, as recommended by the 2017 WHO guidelines, therefore has potential to allow for more precise clinical management.

\section{Invasiveness}

Tumor invasion has been shown to be a consistent prognostic marker in many pituitary adenoma subtypes. ${ }^{58}$ As such, prognostication via genomics with respect to tumor invasion has been well studied in the past, ${ }^{21,55}$ but definitive identification of driving mutations has not yet been achieved. In current clinical practice, invasiveness is determined by radiological studies, and proliferation serves as a proxy for invasive potential, measured via mitotic count and Ki-67 index. ${ }^{35,58}$

More recently, Wang et al..$^{59}$ demonstrated that increased methylation of the LAMA2 gene promoter decreased LAMA2 expression and facilitated pituitary ad- 
enoma invasion within a series comparing invasive to noninvasive adenomas. LAMA2 is a component of laminin, an extracellular matrix protein, and hypermethylation of its promoter has been observed in other malignancies as well. The authors further demonstrated that the invasive potential of LAMA2 is mediated by the PTEN-PI3K/ AKT pathway, a pathway that is targetable by small-molecule inhibitors. More significantly, the group provided in vivo evidence of LAMA2 overexpression or demethylation (using the chemotherapy agent decitabine) significantly suppressing tumor growth, highlighting the clinical potential of the gene as a prognostic marker and the potential application of decitabine as a targeted treatment.

Cheng et al. ${ }^{11}$ investigated genes involved with invasion via genome-wide DNA methylation and RNA microarray analysis in a series of 68 nonfunctioning adenomas (45 null cell adenomas and 23 gonadotroph adenomas). The series was divided by degree of invasiveness for comparison (46 invasive lesions with Knosp grade 3 or 4, and 22 noninvasive lesions otherwise). Results demonstrated 115 differentially expressed genes exhibiting a strong negative correlation between promotor methylation and gene expression levels, 19 of which were involved in established gene ontologies and pathways. Further analysis identified several genes that exhibited a strong positive correlation between methylation and expression. Many of these genes had established roles in oncogenesis. The authors posited these genes as potential markers of tumor invasion and targets for gene therapy.

Another study performed by Yang et al. ${ }^{62}$ demonstrated that caveolin-1, a protein involved in intracellular signaling and known to function as either a tumor suppressor or oncogene in various cancers, was upregulated in invasive pituitary adenomas compared to noninvasive controls. More interestingly, knockdown of the gene resulted in decreased cell migration and invasiveness, highlighting caveolin-1 as an oncogene in this particular subset and as a novel therapeutic target for aggressive lesions. Similarly, Wang et al. ${ }^{59}$ demonstrated that silencing of ADAM12, a membrane metalloprotease with an established role in the EGFR/ERK signaling pathway, impedes tumorigenesis and epithelial-to-mesenchymal transition of pituitary adenomas in vivo.

\section{Management and Response to Therapy}

Treatment of pituitary adenomas typically consists of resection, radiosurgery, dopamine agonists, and somatostatin analogs, along with temozolomide and immunotherapy on a more selective basis. ${ }^{10,38}$ Notable genomic studies of treatment response via these modalities in the past have included the following: $O^{6}$-methylguanine methyltransferase as a marker of response to temozolomide, ${ }^{15} S S T R 2 A$ expression as a marker of response to octreotide, ${ }^{20,21}$ AIP downregulation as marker of response to somatostatin analogs, ${ }^{29,33}$ and low $E R \alpha$ expression as a marker of responsiveness to dopamine agonists. ${ }^{17}$ We note that no studies have investigated links between tumor molecular biology and response to radiation therapy. Both traditional radiation therapy and Gamma Knife radiosurgery are frequently used in the treatment of pituitary adenomas. However, radiation treatment may lead to adverse effects, including loss of residual pituitary function and subsequent hormone insufficiency. Therefore, understanding which tumor types are sensitive to radiation therapy is essential for maximizing the benefit of this treatment modality while minimizing adverse effects.

Somatostatin analogs, such as octreotide, lanreotide, and pasireotide, are often used for management of acromegaly. ${ }^{38}$ Building from prior work showing corticotroph adenomas to have high SST5 expression ${ }^{5,26}$ and from previous clinical studies, a recent phase 3 trial extension performed by Petersenn et al. ${ }^{47}$ indicates that pasireotide may be beneficial to treatment-resistant Cushing disease in the long term. The investigators reported a median percent change of approximately $80 \%$ in mean urinary free cortisol compared to baseline levels among a cohort of 16 patients who received pasireotide therapy for 5 years. Furthermore, patients also experienced clinically significant decreases in blood pressure and body mass index. Only a $-3.5 \%$ median percent change from baseline was observed in tumor volume among a smaller subset of these patients, however.

Dopamine agonists are commonly used as first-line therapy for management of lactotroph adenomas. ${ }^{38}$ Huang et al. ${ }^{27}$ examined $S P K 2$ expression levels in bromocriptineresistant prolactinomas versus normal pituitary, discovering significantly higher levels of gene expression, which also positively correlated with tumor size. The authors postulated that SPK2 may inhibit apoptosis via a p53-dependent mechanism. SPK2 overexpression is well documented in other cancers as well. Furthermore, treatment with bromocriptine prolonged the half-life and increased the expression of SPK2. Using C25, an SPK2 inhibitor, in conjunction with bromocriptine demonstrated increased sensitization and promoted greater apoptosis, highlighting a potential therapeutic approach to drug-resistant prolactinomas. Similarly, Jian et al. ${ }^{30}$ observed decreased levels of miR-145-5p and increased levels of TPT1, a direct target of miR-145-5p, among bromocriptine-resistant prolactinomas, compared to bromocriptine-responsive controls. This study also demonstrated that increasing mIR-145-5p action via an analog increased sensitization to bromocriptine. Yet another study ${ }^{60}$ identified the novel therapeutic targets FOXOl and miR-1299 for treatment of drug-resistant prolactinomas. MiR-1299 was found to be elevated in these tumors, which consequentially decreased $\mathrm{FOXO1}$ expression. FOXO1 binds to the promoter of the PRL gene and inhibits its expression.

Immunotherapy applications for treatment of pituitary adenomas has been examined previously, but results from microarray analyses have been scattered and difficult to reproduce due to small sample sizes. ${ }^{61}$ Using a novel strategy of data integration, Yang et al. ${ }^{61}$ combined existing microarray samples to establish more robust gene markers, discovering 66 potential immune system targets, of which several were proposed by the authors for immunotherapy development.

\section{Translational Opportunities and Future Directions}

Although many important aspects of pituitary adenoma 
tumorigenesis have been detailed above, other factors have been investigated as well. For instance, a role for micro$\mathrm{RNAs}^{34}$ and the potential contribution of cancer stem cells have been described. ${ }^{9,23}$ Other factors, such as tumor microenvironment, angiogenesis, and tumor metabolomics, have not been studied as thoroughly, and interrogation of these pathways may present opportunities for intervention. One factor that has held back the translation of these results into clinically relevant therapeutics is the lack of accurate in vitro and in vivo models. Although a number of mouse models have been developed, few models, if any, accurately reflect the sequence and timeline of sporadic human pituitary tumor development. ${ }^{8}$ The lack of experimental models has also made it difficult to establish an accurate timeline of the sequence of mutations and acquired cellular disturbances.

There are several characteristics of pituitary tumors that might facilitate their treatment. For instance, the pituitary gland lies outside of the blood-brain barrier, which would otherwise be a significant obstacle to the delivery of antitumor agents. Furthermore, many of the genes responsible for pathogenesis of pituitary tumors are intact but epigenetically silenced, a situation that is more readily treated than if the genes in question were irreparably mutated. Last, because the tumor itself is a benign disease, patients can often be satisfactorily treated without the need for complete biological remission, which may indicate that less aggressive treatment strategies may be adequate (in comparison to other neoplasms, which may not be amenable to management as a chronic disease). However, because the tumor is quite indolent and slow growing, traditional cytotoxic agents have a limited role, if any, in treatment, further emphasizing the necessity for targeted therapeutics.

The data we have discussed indicate that epigenetic silencing of tumor suppressors by methylation is a prominent mechanism in pituitary tumor pathogenesis. Although these enzymes are quite targetable by smallmolecule inhibitors, few investigations have tested the efficacy of interventions aimed at epigenetic regulators. Because methylation inhibitors are often cytotoxic, however, another area of exploration might be the use of methylation inhibitors as agents to sensitize the tumor for radiation therapy. Given that radiation therapy primarily functions to induce DNA damage and upregulate pathways involved in apoptosis, senescence, and growth arrest, unleashing downregulated tumor suppressors and their pathways may amplify the therapeutic effect of radiation treatment. Because lack of cell cycle regulation also plays a major role in disease progression, interventions targeted at slowing cell cycle progression, such as CDK4/6 inhibitors, may also be quite efficacious.

\section{Conclusions}

Pituitary adenomas are a complex set of heterogeneous diseases, with each pituitary adenoma having a unique set of molecular and genetic features. These features, in turn, must be taken into consideration when designing novel therapeutic treatment strategies. Pathological epigenetic silencing of tumor suppressors, cell cycle deregulation, and imbalance in activation of proliferation pathways are key processes underlying pituitary adenoma pathogenesis. In the future, genomic and epigenomic classification methods may be used to create a unique tumor identity for each patient, which will serve as the basis for personalized medicine.

\section{References}

1. Ajlan A, Achrol AS, Albakr A, Feroze AH, Westbroek EM, Hwang P, et al: Cavernous sinus involvement by pituitary adenomas: clinical implications and outcomes of endoscopic endonasal resection. J Neurol Surg B Skull Base 78:273282,2017

2. Alexander JM, Biller BMK, Bikkal H, Zervas NT, Arnold A, Klibanski A: Clinically nonfunctioning pituitary tumors are monoclonal in origin. J Clin Invest 86:336-340, 1990

3. Almeida JP, Stephens CC, Eschbacher JM, Felicella MM, Yuen KCJ, White WL, et al: Clinical, pathologic, and imaging characteristics of pituitary null cell adenomas as defined according to the 2017 World Health Organization criteria: a case series from two pituitary centers. Pituitary 22:514-519, 2019

4. Asa SL, Somers K, Ezzat S: The MEN-1 gene is rarely downregulated in pituitary adenomas. J Clin Endocrinol Metab 83:3210-3212, 1998

5. Batista DL, Zhang X, Gejman R, Ansell PJ, Zhou Y, Johnson SA, et al: The effects of SOM230 on cell proliferation and adrenocorticotropin secretion in human corticotroph pituitary adenomas. J Clin Endocrinol Metab 91:4482-4488, 2006

6. Bi WL, Horowitz P, Greenwald NF, Abedalthagafi M, Agarwalla PK, Gibson WJ, et al: Landscape of genomic alterations in pituitary adenomas. Clin Cancer Res 23:1841-1851, 2017

7. Binse I, Ueberberg B, Sandalcioglu IE, Flitsch J, Luedecke DK, Mann K, et al: Expression analysis of GADD $45 \gamma$, MEG3, and p8 in pituitary adenomas. Horm Metab Res 46:644-650, 2014

8. Cano DA, Soto-Moreno A, Leal-Cerro A: Genetically engineered mouse models of pituitary tumors. Front Oncol 4:203, 2014

9. Carreno G, Gonzalez-Meljem JM, Haston S, Martinez-Barbera JP: Stem cells and their role in pituitary tumorigenesis. Mol Cell Endocrinol 445:27-34, 2017

10. Chanson P, Raverot G, Castinetti F, Cortet-Rudelli C, Galland F, Salenave S: Management of clinically non-functioning pituitary adenoma. Ann Endocrinol (Paris) 76:239-247, 2015

11. Cheng S, Xie W, Miao Y, Guo J, Wang J, Li C, et al: Identification of key genes in invasive clinically non-functioning pituitary adenoma by integrating analysis of DNA methylation and mRNA expression profiles. J Transl Med 17:407, 2019

12. Clayton RN, Farrell WE: Clonality of pituitary tumours: more complicated than initially envisaged? Brain Pathol 11:313-327, 2001

13. Clayton RN, Farrell WE: Pituitary tumour clonality revisited. Front Horm Res 32:186-204, 2004

14. Clayton RN, Pfeifer M, Atkinson AB, Belchetz P, Wass JA, Kyrodimou E, et al: Different patterns of allelic loss (loss of heterozygosity) in recurrent human pituitary tumors provide evidence for multiclonal origins. Clin Cancer Res 6:39733982, 2000

15. Dai C, Sun B, Liu X, Bao X, Feng M, Yao Y, et al: O6-Methylguanine-DNA methyltransferase expression is associated with pituitary adenoma tumor recurrence: a systematic meta-analysis. Oncotarget 8:19674-19683, 2017

16. De Sousa SMC, Wang PPS, Santoreneos S, Shen A, Yates CJ, 
Babic M, et al: The genomic landscape of sporadic prolactinomas. Endocr Pathol 30:318-328, 2019

17. Delgrange E, Vasiljevic A, Wierinckx A, François P, Jouanneau E, Raverot G, et al: Expression of estrogen receptor alpha is associated with prolactin pituitary tumor prognosis and supports the sex-related difference in tumor growth. Eur J Endocrinol 172:791-801, 2015

18. Farrell WE, Clayton RN: Molecular pathogenesis of pituitary tumors. Front Neuroendocrinol 21:174-198, 2000

19. Farrell WE, Simpson DJ, Bicknell J, Magnay JL, Kyrodimou E, Thakker RV, et al: Sequence analysis and transcript expression of the MEN1 gene in sporadic pituitary tumours. Br J Cancer 80:44-50, 1999

20. Fougner SL, Borota OC, Berg JP, Hald JK, Ramm-Pettersen $\mathrm{J}$, Bollerslev J: The clinical response to somatostatin analogues in acromegaly correlates to the somatostatin receptor subtype 2a protein expression of the adenoma. Clin Endocrinol (Oxf) 68:458-465, 2008

21. Gatto F, Feelders RA, van der Pas R, Kros JM, Waaijers M, Sprij-Mooij D, et al: Immunoreactivity score using an antisst2A receptor monoclonal antibody strongly predicts the biochemical response to adjuvant treatment with somatostatin analogs in acromegaly. J Clin Endocrinol Metab 98:E66E71, 2013

22. Gruppetta M, Mercieca C, Vassallo J: Prevalence and incidence of pituitary adenomas: a population based study in Malta. Pituitary 16:545-553, 2013

23. Haston S, Manshaei S, Martinez-Barbera JP: Stem/progenitor cells in pituitary organ homeostasis and tumourigenesis. $\mathbf{J}$ Endocrinol 236:R1-R13, 2018

24. Herman V, Fagin J, Gonsky R, Kovacs K, Melmed S: Clonal origin of pituitary adenomas. J Clin Endocrinol Metab 71:1427-1433, 1990

25. Hibberts NA, Simpson DJ, Bicknell JE, Broome JC, Hoban PR, Clayton RN, et al: Analysis of cyclin D1 (CCND1) allelic imbalance and overexpression in sporadic human pituitary tumors. Clin Cancer Res 5:2133-2139, 1999

26. Hofland LJ, van der Hoek J, Feelders R, van Aken MO, van Koetsveld PM, Waaijers M, et al: The multi-ligand somatostatin analogue SOM230 inhibits ACTH secretion by cultured human corticotroph adenomas via somatostatin receptor type 5. Eur J Endocrinol 152:645-654, 2005

27. Huang J, Zhang F, Jiang L, Hu G, Sun W, Zhang C, et al: Inhibition of SKP2 sensitizes bromocriptine-induced apoptosis in human prolactinoma cells. Cancer Res Treat 49:358-373, 2017

28. Jacoby LB, Hedley-Whyte ET, Pulaski K, Seizinger BR, Martuza RL: Clonal origin of pituitary adenomas. J Neurosurg 73:731-735, 1990

29. Jaffrain-Rea ML, Rotondi S, Turchi A, Occhi G, Barlier A, Peverelli E, et al: Somatostatin analogues increase AIP expression in somatotropinomas, irrespective of Gsp mutations. Endocr Relat Cancer 20:753-766, 2013

30. Jian M, Du Q, Zhu D, Mao Z, Wang X, Feng Y, et al: Tumor suppressor miR-145-5p sensitizes prolactinoma to bromocriptine by downregulating TPT1. J Endocrinol Invest 42:639-652, 2019

31. Jiang X, Zhang X: The molecular pathogenesis of pituitary adenomas: an update. Endocrinol Metab (Seoul) 28:245254,2013

32. Jonsson B, Nilsson B: The impact of pituitary adenoma on morbidity. Increased sick leave and disability retirement in a cross-sectional analysis of Swedish national data. Pharmacoeconomics 18:73-81, 2000

33. Kasuki L, Vieira Neto L, Wildemberg LEA, Colli LM, de Castro M, Takiya CM, et al: AIP expression in sporadic somatotropinomas is a predictor of the response to octreotide LAR therapy independent of SSTR2 expression. Endocr Relat Cancer 19:L25-L29, 2012
34. Li XH, Wang EL, Zhou HM, Yoshimoto K, Qian ZR: MicroRNAs in human pituitary adenomas. Int J Endocrinol 2014:435171, 2014

35. Lloyd RV, Osamura YR, Kloppel G, Rosai J: WHO Classification of Tumours of Endocrine Organs, ed 4. World Health Organization, 2017

36. Ma W, Ikeda H, Yoshimoto T: Clinicopathologic study of 123 cases of prolactin-secreting pituitary adenomas with special reference to multihormone production and clonality of the adenomas. Cancer 95:258-266, 2002

37. Ma WB, Ikeda H, Yoshimoto T: [Clinicopathology, clonality, and hormone production profile of prolactinoma.] Zhonghua Yi Xue Za Zhi 85:1382-1387, 2005 (Chinese)

38. Manojlovic-Gacic E, Bollerslev J, Casar-Borota O: Invited Review: Pathology of pituitary neuroendocrine tumours: present status, modern diagnostic approach, controversies and future perspectives from a neuropathological and clinical standpoint. Neuropathol Appl Neurobiol [epub ahead of print], 2019

39. Melmed S: Pathogenesis of pituitary tumors. Nat Rev Endocrinol 7:257-266, 2011

40. Mete O, Lopes MB: Overview of the 2017 WHO Classification of Pituitary Tumors. Endocr Pathol 28:228-243, 2017

41. Mezzomo LC, Gonzales PH, Pesce FG, Kretzmann Filho N, Ferreira NP, Oliveira MC, et al: Expression of cell growth negative regulators MEG3 and GADD45 $\gamma$ is lost in most sporadic human pituitary adenomas. Pituitary 15:420-427, 2012

42. Muşat M, Vax VV, Borboli N, Gueorguiev M, Bonner S, Korbonits M, et al: Cell cycle dysregulation in pituitary oncogenesis. Front Horm Res 32:34-62, 2004

43. Nishioka H, Inoshita N: New WHO classification of pituitary adenomas (4th edition): assessment of pituitary transcription factors and the prognostic histological factors. Brain Tumor Pathol 35:57-61, 2018

44. Ogino A, Yoshino A, Katayama Y, Watanabe T, Ota T, Komine $C$, et al: The $\mathrm{p} 15^{\mathrm{INK} 4 \mathrm{~b}} / \mathrm{p} 16^{\mathrm{INK} 4 \mathrm{a}} / \mathrm{RB} 1$ pathway is frequently deregulated in human pituitary adenomas. J Neuropathol Exp Neurol 64:398-403, 2005

45. Osamura RY, Egashira N, Miyai S, Yamazaki M, Takekoshi S, Sanno N, et al: Molecular pathology of the pituitary. Development and functional differentiation of pituitary adenomas. Front Horm Res 32:20-33, 2004

46. Osamura RY, Kajiya H, Takei M, Egashira N, Tobita M, Takekoshi S, et al: Pathology of the human pituitary adenomas. Histochem Cell Biol 130:495-507, 2008

47. Petersenn S, Salgado LR, Schopohl J, Portocarrero-Ortiz L, Arnaldi G, Lacroix A, et al: Long-term treatment of Cushing's disease with pasireotide: 5 -year results from an open-label extension study of a Phase III trial. Endocrine 57:156-165, 2017

48. Prezant TR, Levine J, Melmed S: Molecular characterization of the men1 tumor suppressor gene in sporadic pituitary tumors. J Clin Endocrinol Metab 83:1388-1391, 1998

49. Reincke M, Sbiera S, Hayakawa A, Theodoropoulou M, Osswald A, Beuschlein F, et al: Mutations in the deubiquitinase gene USP8 cause Cushing's disease. Nat Genet 47:31-38, 2015

50. Ronchi CL, Peverelli E, Herterich S, Weigand I, Mantovani $\mathrm{G}$, Schwarzmayr T, et al: Landscape of somatic mutations in sporadic GH-secreting pituitary adenomas. Eur J Endocrinol 174:363-372, 2016

51. Salomon MP, Wang X, Marzese DM, Hsu SC, Nelson N, Zhang X, et al: The epigenomic landscape of pituitary adenomas reveals specific alterations and differentiates among acromegaly, Cushing's disease and endocrine-inactive subtypes. Clin Cancer Res 24:4126-4136, 2018

52. Shimon I, Melmed S: Genetic basis of endocrine disease: pituitary tumor pathogenesis. J Clin Endocrinol Metab 82:1675-1681, 1997 
53. Simpson DJ, Frost SJ, Bicknell JE, Broome JC, McNicol AM, Clayton RN, et al: Aberrant expression of $G_{1} / S$ regulators is a frequent event in sporadic pituitary adenomas. Carcinogenesis 22:1149-1154, 2001

54. Spoletini M, Taurone S, Tombolini M, Minni A, Altissimi G, Wierzbicki V, et al: Trophic and neurotrophic factors in human pituitary adenomas (Review). Int J Oncol 51:10141024, 2017

55. Suhardja A, Kovacs K, Rutka J: Genetic basis of pituitary adenoma invasiveness: a review. J Neurooncol 52:195-204, 2001

56. Tfelt-Hansen J, Kanuparthi D, Chattopadhyay N: The emerging role of pituitary tumor transforming gene in tumorigenesis. Clin Med Res 4:130-137, 2006

57. Trivellin G, Daly AF, Faucz FR, Yuan B, Rostomyan L, Larco DO, et al: Gigantism and acromegaly due to Xq26 microduplications and GPR101 mutation. N Engl J Med 371:2363-2374, 2014

58. Trouillas J, Roy P, Sturm N, Dantony E, Cortet-Rudelli C, Viennet G, et al: A new prognostic clinicopathological classification of pituitary adenomas: a multicentric case-control study of 410 patients with 8 years post-operative follow-up. Acta Neuropathol 126:123-135, 2013

59. Wang J, Zhang Z, Li R, Mao F, Sun W, Chen J, et al: ADAM12 induces EMT and promotes cell migration, invasion and proliferation in pituitary adenomas via EGFR/ERK signaling pathway. Biomed Pharmacother 97:1066-1077, 2018

60. Xiao Z, Wang Z, Hu B, Mao Z, Zhu D, Feng Y, et al: MiR1299 promotes the synthesis and secretion of prolactin by inhibiting FOXO1 expression in drug-resistant prolactinomas. Biochem Biophys Res Commun 520:79-85, 2019

61. Yang Q, Wang Y, Zhang S, Tang J, Li F, Yin J, et al: Biomarker discovery for immunotherapy of pituitary adenomas: enhanced robustness and prediction ability by modern computational tools. Int J Mol Sci 20:E151, 2019

62. Yang W, Xu T, Qiu P, Xu G: Caveolin-1 promotes pituitary adenoma cells migration and invasion by regulating the interaction between EGR1 and KLF5. Exp Cell Res 367:7-14, 2018
63. Zhang X, Horwitz GA, Prezant TR, Valentini A, Nakashima $\mathrm{M}$, Bronstein MD, et al: Structure, expression, and function of human pituitary tumor-transforming gene (PTTG). Mol Endocrinol 13:156-166, 1999

64. Zhou Y, Zhang X, Klibanski A: Genetic and epigenetic mutations of tumor suppressive genes in sporadic pituitary adenoma. Mol Cell Endocrinol 386:16-33, 2014

65. Zhou Y, Zhong Y, Wang Y, Zhang X, Batista DL, Gejman R, et al: Activation of p53 by MEG3 non-coding RNA. J Biol Chem 282:24731-24742, 2007

\section{Disclosures}

The authors report no conflict of interest concerning the materials or methods used in this study or the findings specified in this paper.

\section{Author Contributions}

Conception and design: all authors. Acquisition of data: Elsarrag, Patel, Chatrath. Analysis and interpretation of data: Elsarrag, Patel, Chatrath. Drafting the article: Elsarrag, Patel, Chatrath. Critically revising the article: Elsarrag, Patel, Chatrath, Taylor. Reviewed submitted version of manuscript: all authors. Approved the final version of the manuscript on behalf of all authors: Jane.

\section{Supplemental Information Videos \\ Video Abstract. https://vimeo.com/415906621.}

\section{Correspondence}

John A. Jane Jr.: University of Virginia Health System, Charlottesville, VA.jaj2k@virginia.edu. 